\title{
Automatic voltage regulation system construction for synchronous generator of a small hydro power plant using thyristor pathogens
}

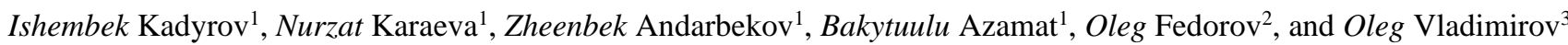 \\ ${ }^{1}$ Kyrgyz national Agrarian University named after K.I. Skryabin. 720005, Bishkek, Kyrgyzstan \\ ${ }^{2}$ Nizhny Novgorod State Technical University n.a. R.E. Alekseev, 603950, Nizhny Novgorod, Russia \\ ${ }^{3}$ Kazan State Power Engineering University, Kazan, Russia
}

\begin{abstract}
The article presents indicators of the hydropower potential of Kyrgyzstan, shows the share of small hydropower plants in the production of electric energy in the energy sector of the republic, reveals the problematic issues that need to be revealed in this work. A brief description of the existing automatic voltage regulation system and automatic field blanking system is given. Based on the analysis of existing systems, their shortcomings were identified and the main functions formulated for automatic voltage regulation systems in both static and dynamic modes associated with starting and stopping the generator, loading and dumping, as well as protective measures taken to ensure reliability operation of the hydraulic unit. The result of the research is the development of the main functional blocks in the system of automatic voltage regulation with a thyristor pathogen and a brief explanation of their work. The synthesis technique of the excitation current regulator of a synchronous generator and the main indicators obtained in the modernization process are shown. In conclusion, all the functions inherent in the modernized system for automatically controlling the excitation of a synchronous generator, aimed at the safe operation of the hydraulic unit, are noted.
\end{abstract}

\section{Introduction}

At present, the hydropower potential of Kyrgyzstan is concentrated in 252 large and medium-sized rivers and is estimated at 18.5 million $\mathrm{kW}$ of power and more than 140-160 billion $\mathrm{kWh}$ of electricity. Moreover, the average slope of mountain rivers varies from 5 to $20 \mathrm{~m}$ per $1 \mathrm{~km}$ of length, and the average specific power is from 2227 to $5322 \mathrm{~kW} / \mathrm{km}$. therefore, the possibilities for building small hydropower stations in the country are unlimited. So far, according to general statistics, the gross share of small hydropower plants in the production of electric energy in the energy sector of the republic is only $1 \%$.

The above figures are useful for investors who invest in priority sectors of the economy, such as the construction of small hydropower plants. Naturally, these small hydropower plants will be equipped with modern equipment with a perfect control system for the economical and safe operation of the hydraulic unit. In this article, we consider the issue of constructing automatic voltage regulation systems operated by small hydropower plants taking into account the realities of today.

Electricity production by several small hydropower plants, concentrated mainly in the Chui oblast of Kyrgyzstan, is carried out by the generating company OJSC «Chakan HPP». The main consumers of these products are companies and business entities of the Chui region and the southern regions of Kazakhstan.

The first several small hydropower plants were put into operation in 1945, and the rest over the next 10 years.

Consequently, the age of the main equipment in these several small hydropower plants is over 60 years old; therefore, they are practically obsolete and require modernization. This primarily concerns the system for automatically controlling the excitation of generators, since in this system the generators themselves become unusable and require continuous inspection and maintenance, most often major repairs. At the same time, frequent blackouts occurring due to the failure of direct current generators and downtime caused by the repair of a machine require the replacement of machine exciters with alternative semiconductor exciters [1-3].

The problem of constructing a system for automatic voltage regulation (AVR) considered in this article, taking into account the replacement of the DC generator with a static thyristor exciter, as a way to extend the life of hydrogenerators.

The experience gained in the development of control systems for frequency-controlled electric drives of excavators proved to be useful in the construction of AVR for synchronous generators, since the control objects in both cases are high-power alternating current machines [4-6]. 
At the same time, for the correct choice of the control structure of the system "Thyristor Pathogens Synchronous Generator" (TP-SG) for a small hydroelectric power station, it is first necessary to identify and list the requirements for the AVR system of synchronous generators based on information obtained in the study of modernized systems, including including automatic field suppresion (AFS) systems.

Fig. 1 shows the most common scheme for including the excitation winding of a synchronous generator in the anchor circuit of the pathogen [7-9]. For SG with significant power (over $100 \mathrm{~kW}$ ), the time constant of the excitation winding $T_{\mathrm{g}}$ is about $1 \mathrm{~s}$ or more. Such inertia delays transients in the processes of switching on and off the excitation winding in the anchor circuit of the pathogen, which may be an undesirable fact. To speed up (speed up) transients, methods are used that reduce the equivalent value of $T_{\mathrm{g}}$ or increase the rate of change of the electromotive force of the synchronous generator by controlling the excitation voltage. The decrease in $T_{\mathrm{g}}$ is possible due to the introduction of an additional resistor $R_{\mathrm{a}}$ in the field winding circuit (see Fig. 1).

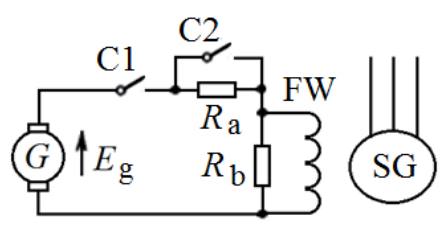

Fig. 1. The circuit of the excitation winding of the synchronous generator to the anchor circuit of the generator to a controlled pathogen.

It is obvious that in order to maintain the nominal value of the electromotive force of the generator, the excitation voltage must be increased by the magnitude of the voltage drop across this resistor in the nominal mode. Another way of boosting is to apply an increased voltage to the field winding during the transient process. At the end of the process, the voltage should be instantly reduced to the required steady state value. This is achieved by introducing a resistor $R_{\mathrm{a}}$ using contact $\mathrm{C} 2$.

The degree of forcing of transients in the diagram of Fig. 1 is characterized by the rate of forcing:

$$
k_{\mathrm{f}}=\frac{R_{\mathrm{b}}+R_{f}}{R_{\mathrm{b}} R_{f}}\left(R_{\mathrm{a}}+\frac{R_{\mathrm{b}} \cdot R_{f}}{R_{\mathrm{b}}+R_{f}}\right) .
$$

Where

$$
R_{\mathrm{a}}=k_{\mathrm{b}} \frac{k_{\mathrm{f}}-1}{k_{\mathrm{f}}+1} R_{f} .
$$

For a given $k_{\mathrm{f}}$, the necessary circuit voltage can be calculated, and using (2) the resistance of the additional resistor. In fig. 2. shows the change in the electromotive force of the excitation and the excitation current during the start-up process for two forcing methods with constantly entered resistance (curves 1 ) and with a cutoff (curves 2). It is obvious that forcing with a cut-off is more effective, since in this case the increased excitation voltage remains unchanged over the entire interval of the transition process.

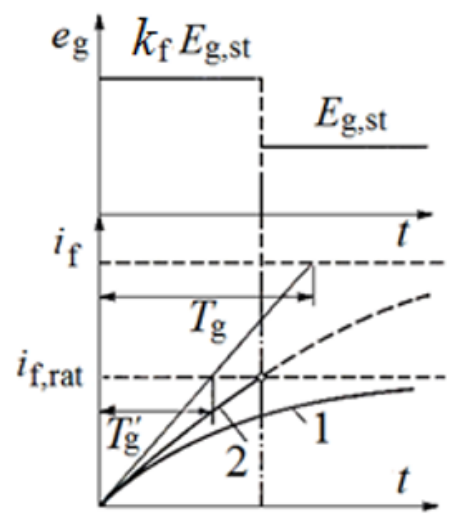

Fig. 2. Graphs of varience in the excitation voltage and the electromotive force of the pathogen during startup with forced.

Consider an automatic field blanking system of the AHL-1 type at the Electrosila plant, which is most often found at modernized small hudropower plants (Fig. 3) [10]. In the field blanking circuit of the Electrosila plant, an automatic machine is used that is equipped with three contacts: main contacts 1 , arcing contacts 2 and arcing lattice 3, representing a system of parallel-connected contacts. Using this machine, the supply voltage from the exciter terminals is supplied to the excitation winding of the synchronous generator. In emergency mode, the circuit breaker trips its main contact 1 and an arc arises on it, then after a short period of time the arcing contact 2 opens. It also arises, which, under the action of an external transverse magnetic field excited by permanent magnets, is drawn into the region of the arcing lattice 3 The arc is divided into a series of series-connected short arcs that burn until the current in the field winding drops to zero.

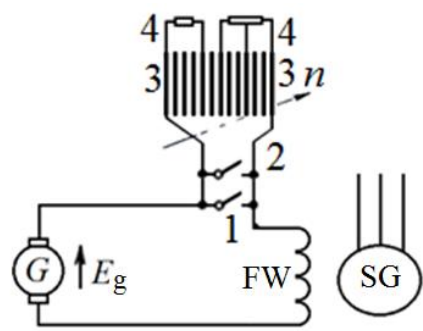

Fig. 3. Scheme automatic field suppression type AHL-1 plant "Electrosila".

The originality of this scheme is that the voltage on the arc $U_{\mathrm{a}}$, located in the lattice, remains constant at all stages of the appearance of arcs and is equal to:

$$
U_{a}=U_{s h} n=\text { const, }
$$

where $U_{\text {sh }}$ - voltage on a short arc located between adjacent plates of the grating; for copper plates $U_{\mathrm{sh}}=25$ $-30 \mathrm{~V} ; \mathrm{n}$ is the number of gaps between the plates.

Thus, the generator protection devices together with the AHL system operate in emergency conditions so that the high-speed protection system timely disconnects the 
synchronous generator from the network, and the AHL system must quickly remove the excitation, i.e. pay off the field. If the AHL system does not work, then the destructive action of the emergency mode will continue due to the current generated by the generator itself $[10$, $11]$.

\section{Research result}

The object of modernization is synchronous generators (SG) of small power plants of the Alamedin cascade, which for 60 years of continuous operation are in a state where modernization, in the first place, of its excitation system became inevitable. In the normal power supply mode, automatic control of the SG excitation provides automatic voltage regulation (AVR) at the terminals of the current collectors, that is, due to the AVR system in the cascade, the static stability of the operation of hydroelectric power plants (HPP) is ensured.In emergency conditions or in the transient mode associated with load shedding and surge, due to the action of automatic voltage regulation, dynamic stability of each hydroelectric power station in the power supply system is connected, interconnected by a single power system. In addition, the automatic voltage control system provides a lightweight option for self-starting of hydrogenerators, creates normal conditions for the alternating voltage generators to be pulled into synchronism [16].

Before modernization, automatic control of excitation in synchronous generators of the Alamedin cascade was carried out from machine exciters, which are driven by a drive from a turbine shaft through a gearbox. These systems are built according to the type of power current compounding with a proportional device for automatic control of excitation, when continuous replenishment is made along the circuit of the main excitation winding of the pathogen. Moreover, to ensure a stable and definite distribution of reactive power between parallel-running cascade generators, the voltage control characteristic at the connection point of the generators should have positive statism in the generator's own current.

The main disadvantage of automatic voltage regulation with an electric machine exciter is that the maximum voltage can only reach twice the rated voltage. Although this voltage is provided to double boost the rotor current, it cannot satisfy the requirements, since the known inertia of the pathogen delays the increase in the excitation current. For this reason, the permissible duration of the stimulation of the excitation may be insufficient in comparison with the possible duration of emergency and post-emergency transients in the power system.

Automatic voltage regulation can also be done by regulating the excitation of a synchronous machine using controlled exciters based on modern semiconductor converters. The advantage of thyristor exciters in the automatic voltage control system is the ability to select the maximum excitation voltage to a 4 -fold value, with which an accelerated increase in the rotor current to a twofold value is provided, after which the force limitation comes into effect.

Fig. 4 shows an exemplary view of the U-shaped characteristics of the generator for various values of power $\mathrm{P}$ and power factor $\cos \varphi$ explaining the principle of current compounding, which combines the process of inertialess control of the stator current.

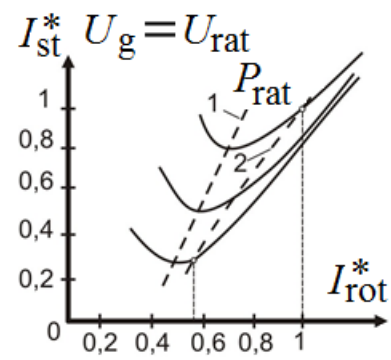

Fig. 4. Compounding characteristics of a synchronous generator.

When constructing a system for automatically controlling the excitation of a synchronous generator with a thyristor exciter, the principle of current compounding will be implemented as a separate unit, called the current compounding unit (CCU). In addition, protective functions such as protection against overloads and short circuits in the external network must be incorporated in the control system of the pathogen.

In the SG stator circuit, the controlled parameters are phase currents in the stator windings, since during synchronous generator overloads the temperature of the windings of the machine can exceed the permissible values. In this case, the protection should work if this excess is observed for a long time, since in the operating mode of the generator there may be short-term excess currents. Therefore, in the control system of the automatic excitation regulator, you must enter the block for calculating the emergency current of the stator of the synchronous generator.

The current in the rotor circuit must also be controlled, since short-term surges in the rotor current can lead to unstable operation of the synchronous generator itself. The control of the SG rotor current should not be carried out along the direct current circuit of the exciter, but along the alternating current circuit from the side of connecting the power unit to the alternating current network. In this case, the unit for calculating the emergency current of the rotor of the synchronous generator will be implemented in the same way as the unit for calculating the emergency current of the synchronous generator.

Finally, as part of the ARV control system, a block of protection against emergency values of the stator currents and the rotor of the synchronous generator must be provided, which will generate a $U_{\log }$ signal, due to which the control signals will be blocked by the power valve of the pulse-phase control system.

Blocks for calculating the emergency current of the stator (BCECS) and rotor (BCECR) of the synchronous generator. To build blocks unit for calculating the emergency current of the rotor of the synchronous 
generator and unit for calculating the emergency current of the synchronous generator having the same structure, you must select the input signals.

The input signals for them can be currents at the controlled points of the synchronous generator and a signal in the control system, taken as a reference.

In fig. 5. at the input of the comparator of the Operational Amplifier 1, the rectified voltages are proportional to the stator currents $\left(U_{\mathrm{a}}, U_{\mathrm{b}}, U_{\mathrm{c}}\right)$ taken from the secondary winding of the CT1 current transformers with the reference voltage. As can be seen from the diagrams (Fig. 5), the output voltage of the comparator can take two values: negative in the case if $\left|U_{\text {ref }}\right| \geq\left|U_{\mathrm{a}}, U_{\mathrm{b}}, U_{\mathrm{c}}\right|, \quad$ and $\quad$ positive if $\left|U_{\text {ref }}\right|<\left|U_{\mathrm{a}}, U_{\mathrm{b}}, U_{\mathrm{c}}\right|$.

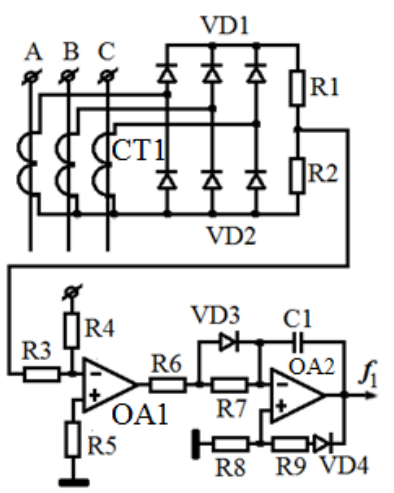

Fig. 5. Schematic diagram of the block calculating the emergency current of the stator of a synchronous generator.

The voltage from the output of the comparator is supplied to the input of the integrator of the Operational Amplifier 2, which has a variable structure, in which the integration process is performed with both a large and a small time constant. A large integrator time constant is set for cases when emergency currents occur at controlled points (the diode at the integrator input is closed). Moreover, in order to avoid false triggering of protection circuits against individual surges (Fig. 6, a), the emergency currents of the stator and rotor are monitored for several periods (see Fig. 6, b). A small time constant is set for normal currents when part of its input resistance is shunted due to an open diode at the input of the integrator.

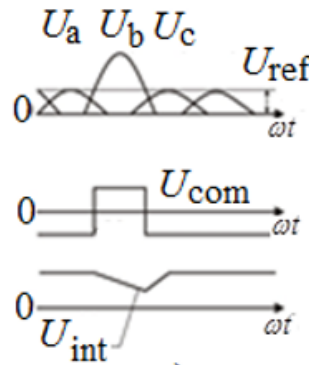

a)
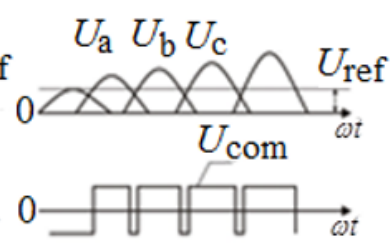
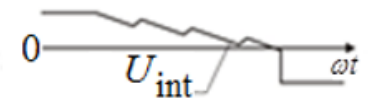

b)
Fig. 6. Voltages at various links of the unit for calculating the emergency current of the rotor of the synchronous generator and unit for calculating the emergency current of the synchronous generator circuits.
With the appearance of a negative voltage at the output of the integrator, positive feedback comes into effect and its output voltage jumps to the bias voltage and this information $\mathrm{fl}$ about the emergency mode will be stored for an arbitrarily long time. For visual observation, the red LED on the board lights up, which is included in the circuit of the external emergency alarm unit.

The block of protection against emergency values of the stator currents and the rotor of the synchronous generator. The signals generated at the output of the unit for calculating the emergency current of the rotor of the synchronous generator and unit for calculating the emergency current of the synchronous generatorare fed to the input of the comparator of the protection unit (Fig. 7) as the emergency value of the stator currents $f_{1}$ or rotor $f_{2}$ of the synchronous generator.In this case, if or, then a voltage close to zero is determined at the output of the comparator, which is determined by the leakage current through the diode VD10. The low voltage of the comparator determines the logic zero level and is applied to the corresponding input of the pulse-phase control system unit, as a result of which the supply of pulses to the control electrodes of the power valves will be blocked and the exciter of the synchronous generator will be disconnected from the network.

\subsection{Pulse-phase control system unit}

Currently, the most widely used synchronous phase shifting system, built as a system with a reference linear voltage. The multichannel principle of forming control pulses is laid in the block of the pulse-phase control system (PPCSU) and has a typical structure. The algorithm for constructing linear phase shift is described in detail in $[15,17]$, therefore, circuit solutions are not given in this paper.

\subsection{Current compounding block}

The system of automatic control of stator current in a synchronous generator is called a compounding device with voltage corrector in the special literature. As a specialist in the field of automated electric drives, it's easier to explain the current compounding unit as a unit of regulators with a proportional stator current regulator and proportionally an integral rotor current regulator according to the circuit shown in Fig. 8. The synthesis of the regulators was carried out using the method of sequential correction[12, 18].

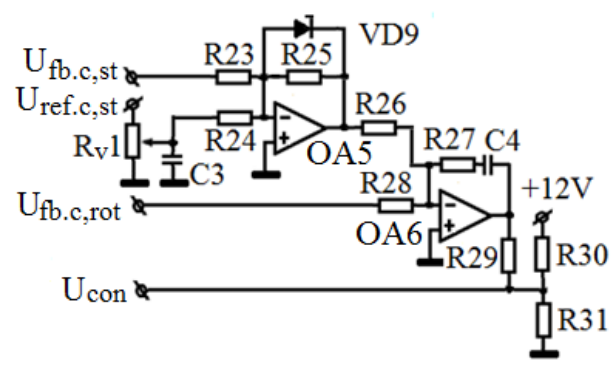

Fig. 7. Schematic diagram of the current compounding unit. 
The proportional stator current regulator is implemented using the Operational Amplifier 1, and proportionally, the integral rotor current regulator is implemented using the Operational Amplifier2. The current compounding unit with a proportional device for automatic control of excitation carries out the process of regulating the stator current of a synchronous generator according to characteristic 2 shown in Fig. 4.

A controlled thyristor exciter operating on the excitation winding of a synchronous generator can be represented by a first-order linear link, as shown in the block diagram (Fig. 8). The absence of intermittent currents contributes to this idea, since the pathogen load is a large inductance [14]. It should be noted that if the thyristor exciter is represented as an inertial unit with a small uncompensated time constant $T_{\mathrm{ta}}=0.01 \mathrm{~s}$, and the excitation coil of the SG by an inertial unit with a large time constant $T_{\mathrm{f}}=0.7 \mathrm{~s}$, then as a result of the synthesis of the control system of the automatic excitation control device by the method of sequential correction, the excitation current controller adopts the structure of the $\mathrm{P}-$ link.

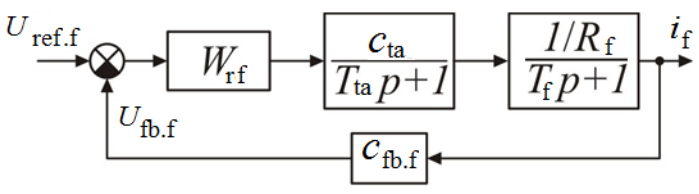

Fig. 8. Block diagram of a field circuit of a synchronous generator.

The oscillogram of the transient process of the increase in the excitation current to the nominal at a single push of the input action is shown in Fig. 9. The proportional part of the regulator ensures the excitation of the pathogen by voltage, reaching up to four times the nominal. With such forcing, an increase in current is achieved for $t_{\mathrm{p}}=0.07 \mathrm{~s}$, which indicates the advantages achieved as a result of the modernization of the automatic excitation control device. [19-25].

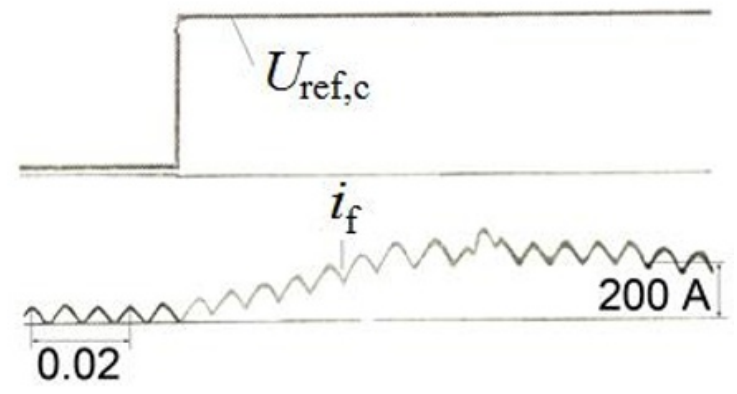

Fig. 9. Oscillogram of the increase in current in the excitation circuit during an abrupt action.

Fig. 10 a shows a schematic diagram of a device for automatically controlling the excitation of a synchronous generator, which shows that the pathogen is assembled according to a bridge circuit and connected to a threephase network through a matching transformer (not shown in the diagram). In this scheme, the task for the stator current, which must be regulated, is carried out using the potentiometer $R_{\mathrm{v} 1}$. The feedback signal on the stator current is taken from the output of the diode bridge VD2, and the signal proportional to the rotor current is taken at the output of the diode bridge VD2. The emergency currents calculated by the the unit for calculating the emergency current of the rotor of the synchronous generator and unit for calculating the emergency current of the synchronous generator are stored and signaled with the help of LEDs, respectively: VD5 - excess of stator current; VD8 - excess current of the rotor.

Fig. 10, $b$ shows a prototype of a device for automatically controlling the excitation of a synchronous generator, in which the control board is shown at the top, the power block in the middle, and the switching and protection equipment below. As can be seen from fig. $11, b$, the thyristor exciter is compactly placed in a small cabinet.

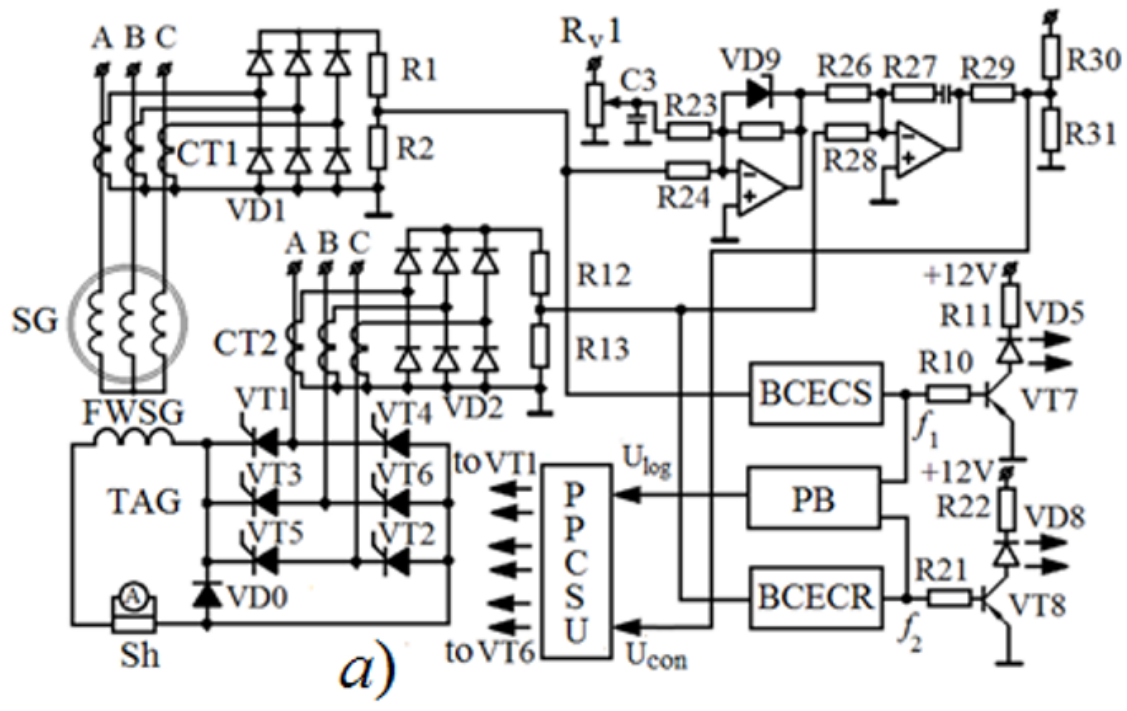

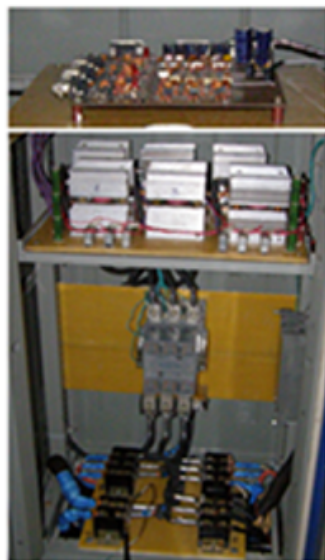

b)

Fig. 10. A device for automatically controlling the excitation of a synchronous generator: a) - schematic diagram; b) - control board and power unit. 


\section{Conclusion}

The current compounding unit, together with the stator and rotor emergency current calculation units, is a system for automatically controlling the excitation of a synchronous generator of small hydroelectric stations, provides the required operating modes of the synchronous generator and performs the necessary protection functions from emergency situations. The forcing of the pathogen by voltage, reaching up to four times the nominal one, ensures high speed of the pathogen, i.e. the current rises and falls during s., which is necessary both in the processes of retraction into synchronism at the time of start-up, and for the quick damping of the generator field in emergency conditions. In its dimensions and adjusting properties, an automatic excitation control device has a noticeable advantage compared to an electric machine exciter.

\section{References}

[1] National Electric Network of Kyrgyzstan [Electronic resource]. Available at: www.nesk.kg/ru/ (accessed: 15.06.2019)

[2] Small hydropower plants as an alternative for Kyrgyzstan [Electronic resource]. Available at: https://knew.kg (accessed: 15.06.2019)

[3] Construction and reconstruction of generating capacities Electronic resource]. Available at: www.invest.kg/ru/ (accessed: 15.06.2019)

[4] I.V. Bochkarev, I.Sh. Kadyrov, Microprocessor control system for the system "Direct frequency converter - AM" of the electric drive of the excavator, Electromechanics 5, 25-30 (2007)

[5] I.Sh. Kadyrov, The study of dynamic processes in the gears of the rotation mechanism of the dragline during the sudden disconnection of the supply voltage, Mining equipment and electromechanics 6, 29-31 (2008)

[6] I.V. Bochkarev, I.Sh. Kadyrov, Optimization of parameters of the control device of the electromechanical system of excavators, Electrical Engineering 2, 2-7 (2009)

[7] V.M. Terekhov, Elements of an automated electric drive (Energoatomizdat, 224, 1987)

[8] A.I. Waldeck, Electric Machines (Energy, 832, 1978)

[9] I.P. Kopylov, Electromechanical energy converters (Energy, 400, 1973)

[10] G.L. Vulman, Operation of generators in power plants (Gosenergoizdat, 344, 1963)

[11] E.I. Gracheva, O.V. Naumov, Operating Mode Influence on Probability Characteristics of Electric Devices, Journal of engineering and applied sciences 11, 1, 2934-2938 (2016)

[12] V.I. Klyuchev, Theory of electric drive (Energoatomizdat, 560, 1985)
[13] M.G. Chilikin, M.M. Sokolov, V.M. Terekhov, Fundamentals of an automated electric drive (Energy, 586, 1974)

[14] V.I. Klyuchev, V.M. Terekhov, Electric drive and automation of general industrial mechanisms (Energy, 360, 2000)

[15] I.Sh. Kadyrov, Design of Electromechanical Systems for Automatic Machines (Publishing Center Teknik, 211, 2006)

[16] P.G. Grudinsky, Electrotechnical Handbook (T. 2, Energy, 752, 1975)

[17] V.S. Rudenko, V.I. Senko, I.M. Chizhenko, Fundamentals of transformative technology (Higher school, 424, 1980)

[18] I.Sh. Kadyrov, Principles, methods and algorithms for constructing microprocessor control systems for electromechanical machine assemblies (Teknik Publishing Center, 200, 2007)

[19] V.A. Bessekersky, E.P. Popov, Theory of automatic control systems (M, Science, 767, 1972)

[20] I.Sh. Kadyrov, T.S. Borukeev, G.D. Matekova, Microprocessor-based system for pulse-phase control of a thyristor converter, News KSTU named after Razzakova 1, 41, I, 36-43 (2017)

[21] O.V. Fedorov, Expeditious forecasting of power consumption, International Conference on Industrial Engineering, Applications and Manufacturing (ICIEAM), 8076221, 1-4 (2017)

[22] Y.I. Gracheva, O.V. Fedorov, Forecasting Reliability Electrotechnical Complexes of InPlant Electric Power Supply Taking into Account Low-Voltage Electrical Apparatuses, International Conference on Industrial Engineering, Applications and Manufacturing (ICIEAM), 5 (2019)

[23] Y.I. Gracheva, O.V. Naumov, Estimation of Power Losses in Electric Devices of the Electrotechnical Complex, International Conference on Industrial Engineering, Applications and Manufacturing (ICIEAM), 6 (2019)

[24] Y.I. Gracheva, O.V. Naumov, A.N. Gorlov, Influence of value resistance contact units of switching devices on losses of the electric power in shop networks of low tension, IOP Conference Series: Materials Science and Engineering, 6 (2019)

[25] Y.I. Gracheva, A.N.Alimova, Calculating Probability of Faultless work of Shop Nets with the Help of Coefficients of Ratio, International Russian Automation Conference (RusAutoCon), 3-6 (2019) 